九州大学学術情報リポジトリ

Kyushu University Institutional Repository

\title{
日本人における肥厚性硬膜炎 臨床疫学調査
}

米川，智

ht tps://doi.org/10.15017/1789442

出版情報：Kyushu University，2016，博士（医学），論文博士 バージョン:

権利関係: Fulltext avai lable. 
RESEARCH PAPER

\title{
A nationwide survey of hypertrophic pachymeningitis in Japan
}

\author{
Tomomi Yonekawa, ${ }^{1}$ Hiroyuki Murai, ${ }^{1}$ Satoshi Utsuki, ${ }^{2}$ Takuya Matsushita, ${ }^{1}$ \\ Katsuhisa Masaki, ${ }^{1}$ Noriko Isobe, ${ }^{1}$ Ryo Yamasaki, ${ }^{3}$ Mari Yoshida, ${ }^{4}$ Susumu Kusunoki, ${ }^{5}$ \\ Kiyomi Sakata, ${ }^{6}$ Kiyotaka Fujii, ${ }^{2}$ Jun-ichi Kira ${ }^{1}$
}

- Additional material is published online only. To view please visit the journal online (http://dx.doi.org/10.1136/ jnnp-2013-306410)

${ }^{1}$ Department of Neurology, Neurological Institute, Graduate School of Medical Sciences, Kyushu University, Fukuoka, Japan

${ }^{2}$ Department of Neurosurgery, Kitasato University School of Medicine, Sagamihara, Japan ${ }^{3}$ Department of Neurological Therapeutics, Neurological Institute, Graduate School of Medical Sciences, Kyushu University, Fukuoka, Japan ${ }^{4}$ Department of Neuropathology, Institute for Medical Science of Aging, Aichi Medical University, Nagakute, Japan

${ }^{5}$ Department of Neurology, School of Medicine, Kinki University, Osaka, Japan ${ }^{6}$ Department of Hygiene and Preventive Medicine, Iwate Medical University School of Medicine, Morioka, Japan

Correspondence to Professor Jun-ichi Kira, Department of Neurology, Neurological Institute, Graduate School of Medical Sciences, Kyushu University, 3-1-1 Maidashi, Higashi-ku, Fukuoka 812-8582, Japan; kira@neuro.med.kyushu-u.ac.jp

Received 26 July 2013 Revised 25 October 2013 Accepted 3 November 2013

To cite: Yonekawa T, Murai $\mathrm{H}$, Utsuki $\mathrm{S}$, et al. J Neurol Neurosurg Psychiatry Published Online First: [please include Day Month Year] doi:10.1136/ jnnp-2013-306410

\section{ABSTRACT}

Objectives To clarify the prevalence, frequent causes and distinct features of hypertrophic pachymeningitis (HP) according to background conditions in a nationwide survey in Japan.

Methods The study began with a preliminary survey to determine the approximate number of HP patients diagnosed from 1 January 2005 to 31 December 2009, and was followed by a questionnaire survey for clinical and laboratory findings. HP was defined as a condition with thickening of the cranial or spinal dura mater with inflammation, evidenced by MRI or histology.

Results Crude HP prevalence was 0.949/100 000 population. The mean age at onset was $58.3 \pm 15.8$ years. Among 159 cases for whom detailed data were collated, antineutrophil cytoplasmic antibody (ANCA)-related HP was found in 54 cases (34.0\%) and lgG4/multifocal fibrosclerosis (MFS)-related HP in 14 cases (8.8\%). Seventy cases (44.0\%) were classified as 'idiopathic' and 21 (13.2\%) as 'others'. ANCA-related HP cases showed a female preponderance, a higher age of onset, and higher frequencies of otological symptoms and elevated systemic inflammatory biomarkers, but lower frequencies of diplopia compared with idiopathic HP. IgG4/MFS-related HP cases showed a marked male predominance; all had cranial HP while none had isolated spinal HP or decreased sensation. Conclusions HP is not extremely rare. ANCA-related HP is the most frequent form, followed by lgG4/MFS-related HP. Both forms have unique features, which may help to differentiate background causes.

\section{INTRODUCTION}

Cranial and spinal hypertrophic pachymeningitis (HP) is a rare inflammatory disorder demonstrating local or diffuse thickening of the intracranial or spinal dura mater. Thickening of the dura mater causes intracranial hypertension, cranial nerve palsy and spinal cord dysfunction. MRI findings show thickening and contrast enhancement of the affected dura mater. HP pathology shows interstitial fibrosis and inflammatory cell infiltration consisting mainly of lymphocytes. HP is aetiologically heterogeneous, secondarily developing in association with a variety of conditions, such as infection, autoimmune disease, trauma and tumours, or being labelled idiopathic in the absence of an identifiable cause. $^{1} 2$ The mechanisms underlying idiopathic $\mathrm{HP}$ are thus ill defined, and unidentified causes might exist. Because there have been no epidemiological or large-scale clinical studies of HP, its prevalence, frequent causes and distinct features according to background conditions are totally unknown. Therefore, we aimed to clarify these issues in a nationwide survey of HP in Japan.

\section{METHODS}

Procedures

The nationwide survey was conducted by the Research Committee of HP, sponsored by the Ministry of Health, Labour and Welfare, Japan. This study was approved by the Kyushu University Ethics Committee. The survey was undertaken in two steps: first, a preliminary survey to ascertain the approximate number of HP patients in Japan, and second, a survey using a questionnaire sheet for each patient. The hospitals studied were randomly selected from the directory of all registered hospitals in Japan. Selection was made according to stratification based on the number of beds in each hospital; the more beds a hospital had, the higher its probability of being selected. ${ }^{3} \mathrm{HP}$ was defined as a thickening of the cranial or spinal dura mater with inflammation, and cases in whom either thickening of the dura mater was detected by MRI, or fibrotic thickening with inflammatory cell infiltration was observed in biopsied dura mater, were included. We excluded cases associated with malignancy and intracranial hypotension.

The questionnaire for the preliminary survey on HP patients who, because of the disease, visited hospitals from 1 January 2005 to 31 December 2009 was mailed to 5477 hospital departments (446 neurology, 731 neurosurgery, 994 internal medicine, 951 orthopaedics, 770 otorhinolaryngology, 800 paediatrics and 785 ophthalmology departments) together with the inclusion criteria. Following the collection and collation of the results of the first questionnaire, the second questionnaire was forwarded to those reporting patients in the first survey. It requested detailed clinical information on individual patients including age at onset and examination, sex, symptoms based on history and signs based on neurological examination, coexisting diseases, laboratory findings, MRI findings of brain and spinal cords, pathological findings, clinical course, treatment and prognosis. Patients reported by more than one hospital or department were treated as duplicate.

Laboratory findings included myeloperoxidase (MPO)- and proteinase-3 (PR3)-antineutrophil cytoplasmic antibody (ANCA) positivity, and elevation of 
IgG4. We further classified cases into several categories according to positive findings for ANCA, IgG4 elevation and coexisting diseases. Patients were regarded as having ANCA-related HP if either MPO-ANCA or PR3-ANCA was detected, or ANCA-related diseases (ANCA-related angiitis or Wegener's granulomatosis) coexisted. Diagnosis of IgG4/multifocal fibrosclerosis (MFS)-related $\mathrm{HP}$ was based on the established criteria for IgG4-related disease ${ }^{4}$ (clinical examination showing characteristic diffuse/local swelling or mass in single or multiple organs, elevated serum IgG4 levels $>135 \mathrm{mg} / \mathrm{dL}$, and IgG4-positive plasma cells in the biopsied dura with a IgG4-positive/IgG-positive cell ratio $>40 \%$ and more than 10 IgG4 + plasma cells per high-power field), or the presence of MFS, such as retroperitoneal fibrosis, mediastinal fibrosis, sclerosing pancreatitis, Riedel's thyroiditis and pseudotumour of the orbit. Idiopathic HP comprised cases with no evidence of ANCAor IgG4/MFS-related conditions, or without other causes including relevant infections asked about in the second survey, such as syphilis, tuberculosis, fungal infections (candidiasis, aspergillosis), bacterial infections (Pseudomonas aeruginosa, Propionibacterium acnes), borreliosis and cysticercosis.

\section{Statistical analysis}

The estimated total number of HP patients in Japan was extrapolated from our data using formulae derived by the epidemiology committee, ${ }^{3} 5$ taking response rates into account. First, for each stratum, the total reported number of patients was divided by the ratio of responding institutions to the number of surveyed institutions. The results for all strata were then added to estimate the total number of HP patients. ${ }^{5}$ Statistical analyses of numerical variables were initially performed using the Pearson's $\chi^{2}$ test and Kruskal-Wallis test. When statistical significance was found, Pearson's $\chi^{2}$ test or Fisher's exact test was used to determine the statistical significance of differences between groups. Uncorrelated p values were corrected by multiplying them by the number of comparisons (Bonferroni-Dunn's correction) to calculate corrected $\mathrm{p}$ values. Differences in ratios between two groups were tested for significance by the $\chi^{2}$ test or Fisher's exact test when the criteria for the $\chi^{2}$ tests were not fulfilled. In all assays, $\mathrm{p}$ values $<0.05$ were considered statistically significant.

\section{RESULTS}

\section{Baseline characteristics}

In the preliminary survey, 1904 departments (34.8\%) responded, reporting $324 \mathrm{HP}$ patients. In the second questionnaire, detailed clinical data on 159 patients $(49.1 \%$ of those reported in the preliminary survey) were collected. The estimated crude prevalence was $0.949 / 100000$ population $(95 \% \mathrm{CI}$ 0.833 to 1.065 ). The male to female ratio was 1:0.91 (table 1 ). The mean age at onset was $58.3 \pm 15.8$ years, and mean age at first visit to the physician was $59.7 \pm 15.2$ years. HP diagnosis was made by MRI alone in 106 cases, MRI and pathology in 49 cases, and pathology alone in four cases.

Table 1 Demographic features of the 159 patients with hypertrophic pachymeningitis

\begin{tabular}{|c|c|c|c|}
\hline Basic demographics & & Initial symptoms & Number (\%) \\
\hline Number of cases analysed & 159 & Headache & $56(35.2)$ \\
\hline Sex ratio (male:female) & $1: 0.91$ & Visual loss & $21(13.2)$ \\
\hline Age at onset (mean $\pm S D$, years) & $58.3 \pm 15.8$ & Double vision & $20(12.6)$ \\
\hline Age at first visit to physician (mean $\pm S D$, years) & $59.7 \pm 15.2$ & Otological symptoms & $15(9.4)$ \\
\hline Disease duration (mean $\pm \mathrm{SD}$, months) & $48.3 \pm 50.9$ & Symptoms during entire course & Number $(\%)$ \\
\hline Underlying diseases & Number & Headache & $113(71.1)$ \\
\hline ANCA-related angiitis & 21 & Back pain & $6(3.8)$ \\
\hline Wegener's granulomatosis & 19 & Fever & $42(26.4)$ \\
\hline Multifocal fibrosclerosis & $6^{*}$ & Consciousness disturbance & $21(13.2)$ \\
\hline IgG4-related disease & 9 & Convulsion & $14(8.8)$ \\
\hline Otitis media & 3 & Memory disturbance and other higher brain dysfunction & $11(6.9)$ \\
\hline Cholesteatoma of the middle ear & 1 & Visual loss & $52(32.7)$ \\
\hline Sinusitis & 1 & Double vision & $46(28.9)$ \\
\hline Sjögren syndrome & 2 & Dysphagia & $13(8.2)$ \\
\hline Tuberculosis & 2 & Dysarthria & $11(6.9)$ \\
\hline Aspergillosis & 2 & Weakness (facial and/or extremities) & $38(23.9)$ \\
\hline Site of dural hypertrophy & Number (\%) & Sensory disturbance & $45(28.3)$ \\
\hline Cranial & $135(84.9)$ & Bladder disturbance & $10(6.3)$ \\
\hline Spinal & $14(8.8)$ & Bowel disturbance & $7(4.4)$ \\
\hline Cranial and spinal & $7(4.4)$ & Neurological findings & Number $(\%)$ \\
\hline Mode of onset & Number (\%) & Cranial nerve palsy & $99(62.3)$ \\
\hline Acute & $41(25.8)$ & Neck stiffness & $7(4.4)$ \\
\hline Subacute & $75(47.2)$ & Motor impairment & $26(16.4)$ \\
\hline Chronic & $27(17.0)$ & Abnormal tendon reflexes & $44(27.7)$ \\
\hline Clinical course & Number (\%) & Pathological reflexes & $15(9.4)$ \\
\hline Monophasic & $51(32.1)$ & Limb and/or truncal ataxia & $6(3.8)$ \\
\hline Progressive & $28(17.6)$ & Decreased sensation & $31(19.5)$ \\
\hline Relapsing-remitting & $62(39.0)$ & Sphincter dysfunction & $5(3.1)$ \\
\hline Unknown & $18(11.3)$ & & \\
\hline
\end{tabular}


Table 2 Cranial nerve involvement in hypertrophic pachymeningitis patients

\begin{tabular}{lc}
\hline & $\mathrm{n} / \mathrm{N}(\%)$ \\
\hline Cranial nerve involvement & $99 / 159(62.3)$ \\
Single & $40 / 99(40.4)$ \\
Multiple & $59 / 99(59.6)$ \\
Cranial nerves & $\mathrm{n} / \mathrm{N}(\%)$ \\
I & $2 / 99(2.0)$ \\
II & $41 / 99(41.4)$ \\
III & $30 / 99(30.3)$ \\
IV & $25 / 99(25.3)$ \\
V & $19 / 99(19.2)$ \\
VI & $35 / 99(35.4)$ \\
VII & $19 / 99(19.2)$ \\
VIII & $27 / 99(27.3)$ \\
IX & $13 / 99(13.1)$ \\
X & $10 / 99(10.1)$ \\
XI & $5 / 99(5.1)$ \\
XII & $8 / 99(8.1)$ \\
\hline n, number of involved cases, N, number of cases collated, or total number of involved \\
cases.
\end{tabular}

The diseases underlying HP were heterogeneous. ANCA-related angiitis and Wegener's granulomatosis were the most common coexisting diseases. IgG4/MFS-related diseases followed. Among 14 cases diagnosed as having IgG4/MFS-related HP, four cases had retroperitoneal fibrosis and were thus regarded as having MFS-related HP. The remaining 10 cases were diagnosed as having IgG4-related HP based on the IgG4-related disease criteria ${ }^{4}$; one had definite IgG4-related disease (IgG4 + cells in biopsied dura, elevated serum IgG4 concentrations and diffuse/local organ swelling or mass), six of these had probable IgG4-related HP (IgG4+ cells in biopsied dura and diffuse/local organ swelling or mass), and three had possible IgG4-related HP (elevated serum IgG4 concentrations and diffuse/local organ swelling or mass). Otorhinolaryngological disorders, such as otitis media and sinusitis, occasionally accompanied. Infectious causes were rarely identified, with only two cases with tuberculosis and two cases of aspergillosis. HP was confined to the cranial dura in 137 cases (86.2\%), the spinal dura in $15(9.4 \%)$, and both in $7(4.4 \%)$ (demographic features according to the sites of HP are shown in online supplementary table S1). Approximately half the HP cases had subacute onset, whereas, the rest showed either an acute or chronic pattern. More than 50\% of HP patients showed either a relapsing-remitting or progressive course.

\section{Symptoms and neurological findings}

Headache was the most common initial symptom of HP (35.2\%), followed by ophthalmological symptoms, such as visual loss and double vision (each $13.2 \%$ and $12.6 \%$, respectively) (table 1). Some patients (9.4\%) had otological symptoms including deafness and tinnitus. During the entire course, the frequency of headache rose to $71.1 \%$. Fever was seen in onequarter of HP patients. Visual loss and double vision were observed in approximately one-third of HP patients, compared with $<10 \%$ for dysphagia and dysarthria. Neurological findings revealed frequent involvement of the cranial nerves (62.3\%). Multiple involvements were more common than isolated involvement, and cranial nerves II-VIII were more frequently affected than IX-XII (table 2). Although headache was the most frequent symptom, neck stiffness was uncommon (4.4\%). Abnormal tendon reflex and decreased sensation were seen in approximately one-quarter of HP patients. Ataxia and sphincter dysfunction were relatively rare.

\section{Laboratory findings in peripheral blood and CSF}

Non-specific inflammation was seen in a half to three-quarters of HP cases, such as increased erythrocyte sedimentation rate (ESR), white blood cells (WBC) or C-reactive protein (CRP) (table 3). Antinuclear antibody was detected in $16.9 \%$ of cases

Table 3 Laboratory, neuroimaging, and pathological findings in 159 hypertrophic pachymeningitis cases

\begin{tabular}{|c|c|c|c|}
\hline Laboratory findings & $\mathrm{n} / \mathrm{N}(\%)$ & Neuroimaging & $\mathrm{n} / \mathrm{N}(\%)$ \\
\hline Blood & & MRI & \\
\hline ESR elevation & $78 / 104(75.0)$ & Thickening of the cranial dura mater & $141 / 156(90.4)$ \\
\hline WBC increase & $63 / 146(43.2)$ & Gd enhancement of cranial dura & 124/139 (89.2) \\
\hline CRP elevation & $110 / 149(73.8)$ & Thickening of the spinal dura mater & $21 / 54(38.9)$ \\
\hline ANA elevation & 20/118 (16.9) & Gd enhancement of spinal dura & $17 / 20(85.0)$ \\
\hline MPO-ANCA positivity & $33 / 119(27.7)$ & Gallium scintigraphy & \\
\hline PR3-ANCA positivity & 14/111 (12.6) & Increased uptake & $22 / 50(44.0)$ \\
\hline IgG4 elevation & $7 / 27(25.9)$ & SPECT & \\
\hline STS & $2 / 122(1.6)$ & Hypoperfusion & $7 / 29(24.1)$ \\
\hline Anti-HTLV-1 Ab & $1 / 50(2.0)$ & Hyperperfusion & $3 / 29(10.3)$ \\
\hline ADA elevation & $3 / 28(10.7)$ & PET & \\
\hline ACE elevation & $1 / 56(1.8)$ & Positive accumulation & 2/17 (11.8) \\
\hline CSF & & Pathological findings of dura mater & $\mathrm{n} / \mathrm{N}(\%)$ \\
\hline Pleocytosis & $71 / 116(61.2)$ & Fibrosis & $43 / 52(82.7)$ \\
\hline Protein elevation & 115/119 (99.6) & Infiltration of inflammatory cells & $47 / 52(90.4)$ \\
\hline TPLA positivity & $0 / 7(0.0)$ & Angiitis & $4 / 52(7.7)$ \\
\hline \multirow[t]{4}{*}{ ADA elevation } & $2 / 22(9.1)$ & Granuloma & $15 / 52(28.8)$ \\
\hline & & Necrosis & $8 / 52(15.4)$ \\
\hline & & Oedema & $5 / 52(9.6)$ \\
\hline & & IgG4-positive plasma cells & $11 / 42(26.2)$ \\
\hline
\end{tabular}

Ab, antibody; ADA, adenosine deaminase; ANA, antinuclear antibody; CRP, C-reactive protein; CSF, cerebrospinal fluid; ESR, erythrocyte sedimentation rate; Gd, gadolinium; HTLV-1, human T-lymphotrophic virus type I; MPO-ANCA, myeloperoxidase-antineutrophil cytoplasmic antibodies; PET, positron emission tomography; PR3-ANCA, proteinase-3-antineutrophil cytoplasmic antibodies; SPECT, single photon emission CT; STS, serologic test for syphilis; TPLA, treponema pallidum latex agglutination; WBC, white blood cells. 
assessed, and adenosine deaminase (ADA) was elevated in $10.7 \%$. Serologic tests for syphilis and human T-lymphotrophic virus type 1 antibody were rarely positive $(1.6 \%$ and $2.0 \%$, respectively). The most noticeable finding was that MPO-ANCA and PR3-ANCA were positive in 33/119 (27.7\%) and 14/111 $(12.6 \%)$ cases assessed, respectively. In four cases, MPO-ANCA and PR3-ANCA were detected. As a result, 43 cases were ANCA-positive. Furthermore, hyper-IgG4aemia was observed in 7/27 (25.9\%) cases examined. Cerebrospinal fluid (CSF) pleocytosis was detected in $71 / 116(61.2 \%)$ cases, while variable degrees of protein elevation were found in 115/116 (96.6\%) cases. ADA elevation in the CSF was found in $2 / 22(9.1 \%)$ cases.

\section{Neuroimaging}

On brain MRI, hypertrophic change of the cranial dura mater was found in 141/156 (90.4\%) cases examined (table 3). Gadolinium (Gd) enhancement was observed in 124/139 (89.2\%). Hypertrophic changes of the spinal dura mater were found in 21/54 (38.9\%) cases examined, while Gd-enhancement was seen in $17 / 20(85.0 \%)$. Thickening of the cranial dura mater was diffuse in 33/141 (23.4\%) cases and partial in 108/ 141 (76.6\%). Increased uptake in gallium scintigraphy was found in 22/50 (44.0\%). Abnormalities in single photon emission CT (SPECT) and positron emission tomography (PET) findings were observed in $10 / 29$ (34.5\%) cases and $2 / 17$ $(11.8 \%)$ cases, respectively.

\section{Pathological findings}

Fifty-two patients underwent biopsy of the dura mater (table 3). The main pathological findings were fibrosis (82.7\%), inflammatory cell infiltration (monocytes, plasma cells, eosinophils and polymorphonuclear leucocytes) (90.4\%) and granuloma $(28.8 \%)$. Necrosis and oedema were found in some cases. Importantly, IgG4-positive cells were found in 11/42 (26.2\%) cases assessed; seven in IgG4/MFS-related HP and four in ANCA-related HP. Importantly, IgG4-positive cells were found in $11 / 42(26.2 \%)$ cases assessed. Angiitis was detected in $4 / 52$ cases $(7.7 \%)$. Culture of the biopsied dura mater in 27 patients identified tuberculosis in one while the rest were negative. The brain adjacent to thickened dura mater was biopsied in eight cases, revealing infiltration of inflammatory cells in seven, while granuloma and necrosis were each observed in four cases, and IgG4-positive cells in one.

\section{Treatment}

Selected treatment options in our HP series are listed in online supplementary table S2. In 12 cases of infectious HP, antibiotic, antifungal, and antituberculosis drugs were used as the first-line therapy for relevant pathogens. Corticosteroids, mostly methylprednisolone pulse therapy followed by oral administration, were administered as the first choice for HP when infectious cases were excluded. A total of 94 cases received corticosteroids as immunotherapy at first, resulting in an $87.2 \%$ improvement. In 54 cases with insufficient response to corticosteroids, immunosuppressants were added and $92.6 \%$ improved. Only 24 cases $(15.1 \%)$ required surgery.

\section{Comparison of idiopathic, ANCA-related and IgG4/MFS-related HP}

According to the classification stated in the section on Methods, ANCA-related and IgG4/MFS-related diseases are the two major causes of HP in Japan (figure 1A,B). There were 48 (30.2\%) and $14(8.8 \%)$ cases of ANCA-related and IgG4/MFS-related
HP, respectively. Six patients (3.8\%) with ANCA-related HP also had either hyper-IgG4aemia or IgG4-positive plasma cells in the biopsied dura (combined cases in figure 1A,B). Such cases were included in the ANCA-related HP group in the following analyses because they showed similar features to ANCA-related HP and ANCA-related disease could show hyper-IgG4aemia. Idiopathic HP comprised 44.0\% (70/159) of cases while various other causes were responsible for $13.2 \%(21 / 159)$.

Comparisons of demographic features among idiopathic, ANCA-related and IgG4/MFS-related HP revealed a male predominance for idiopathic HP (male:female=1:0.75) and a female preponderance for ANCA-related HP (1:1.34) (table 4). Interestingly, IgG4/MFS-related HP showed a marked male predominance (1:0.17). Thus, sex ratios were significantly different among the three groups. All IgG4/MFS-related HP cases exhibited cranial HP; none showed isolated spinal HP, while isolated spinal HP was occasionally seen in idiopathic and ANCA-related HP (12.9\% and 5.6\%, respectively). Age of onset was significantly older in ANCA-related HP cases than in idiopathic HP cases. There was no significant difference in the mode of onset and clinical course among the three groups; however, ANCA-related HP cases less frequently developed acute onset while IgG4/MFS-related HP cases tended to show a monophasic course more frequently than did the others $(p=0.0553)$.

As initial symptoms, ANCA-related HP cases showed a higher frequency of otological symptoms but lower frequency of double vision, compared with idiopathic HP cases (see table 4 and online supplementary figure S1). Regarding symptoms and signs during the entire course, ANCA-related HP cases had significantly greater frequency of fever compared with idiopathic HP, and lower frequency of double vision compared with idiopathic and IgG4/MFS-related HP cases. Sensory disturbance was more common in idiopathic HP cases than ANCA-related and IgG4/MFS-related HP cases. Systemic inflammatory responses, such as elevated ESR and CRP, and increased WBC, were more frequently found in ANCA-related HP compared with idiopathic HP.

\section{DISCUSSION}

This nationwide epidemiological survey of HP in Japan enabled us to elucidate the prevalence and clinical characteristics of HP. This is epoch-making because there has been no previous epidemiological survey of HP, with a series of approximately 10 patients being the largest. ${ }^{1} 6$ The main new findings of the present study are as follows: (1) crude HP prevalence was determined to be $0.949 / 100000$; (2) among all HP cases, the most common cause is ANCA-related HP, making up as much as $34.0 \%$ of all cases, and the second most common cause is IgG4/ MFS-related HP, making up $8.8 \% \quad(12.6 \%$, if including ANCA-related HP cases with hyper-IgG4aemia); (3) ANCA-related HP showed a female preponderance, a higher age at onset, and higher frequencies of otological symptoms and elevated systemic inflammatory markers compared with idiopathic HP, but lower frequencies of diplopia compared with idiopathic and IgG4/MFS-related HP; (4) IgG4/MFS-related HP showed a marked male predominance, and all IgG4/MFS-related HP patients had cranial HP while none had isolated spinal HP, resulting in a lower frequency of decreased sensation compared with idiopathic HP patients who occasionally had spinal HP.

However, our study has some limitations. First, the rate of response to the preliminary survey was not very high; however, the estimated number of HP patients in Japan was calculated by taking the response rate in each stratum into account. ${ }^{5}$ The response rate in the secondary survey was reasonably high 


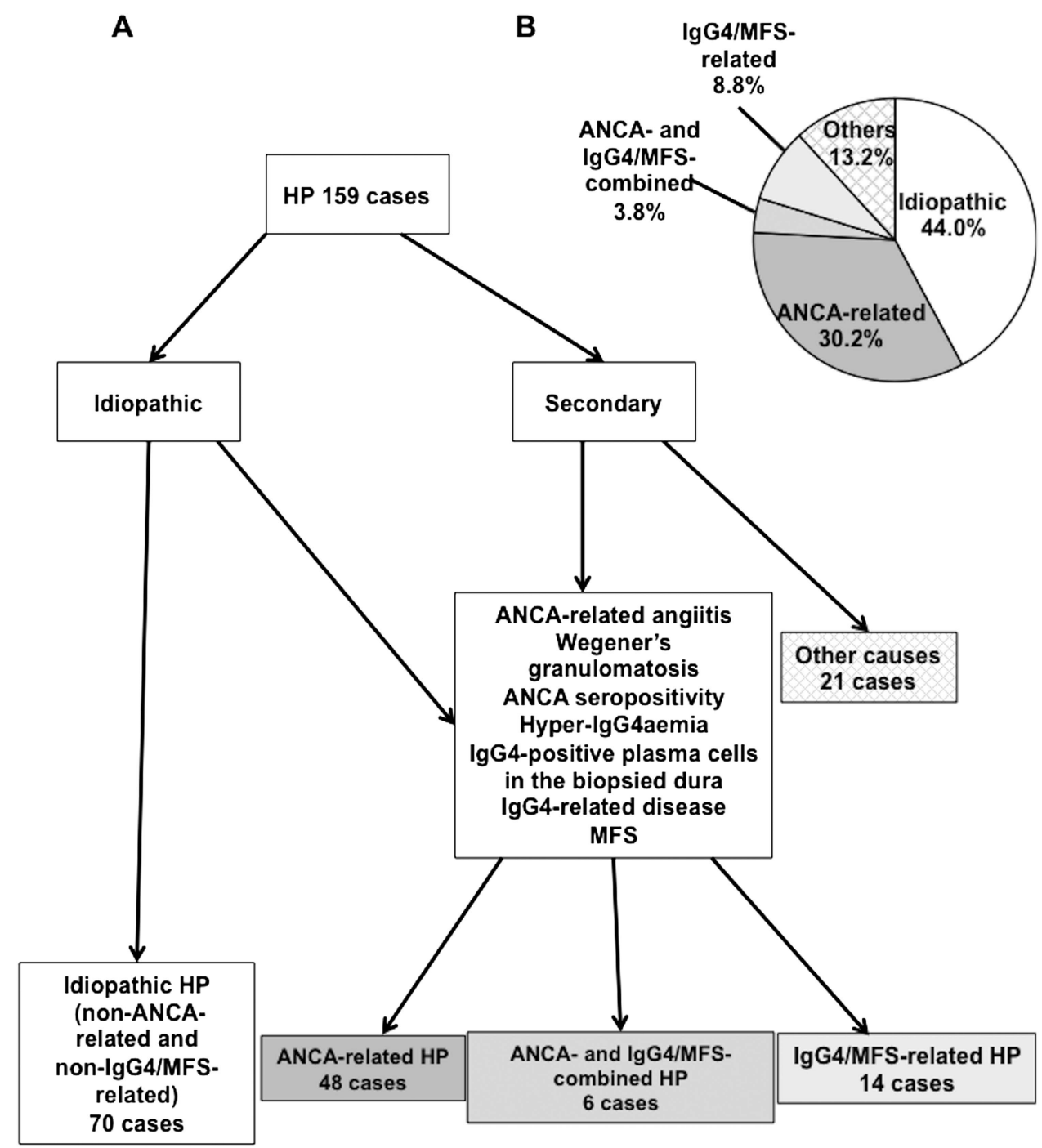

Figure 1 Classification of hypertrophic pachymeningitis (HP) in the present nationwide survey in Japan. (A) Flow chart showing the classification of the 159 HP patients. Causes of HP, idiopathic or secondary, were initially judged by the physician in charge. We classified 70 cases as having idiopathic HP because neither antineutrophil cytoplasmic antibody (ANCA)-related nor IgG4/multifocal fibrosclerosis (MFS)-related systemic diseases was present. We extracted 68 cases with ANCA-related angiitis, Wegener's granulomatosis, ANCA-seropositivity, hyper-IgG4aemia, IgG4-positive plasma cells in the biopsied dura mater, IgG4-related disease, and MFS from cases with secondary HP and those initially judged as 'idiopathic HP' by the physician in charge. We further divided them into 48 cases with ANCA-related HP, 14 cases with IgG4/MFS-related HP, and six cases with combined ANCA-related and IgG4/MFS-related HP. (B) Proportions of idiopathic and secondary HP according to the major underlying diseases. Idiopathic HP accounts for $44.0 \%$ of all cases while ANCA-related and IgG4/MFS-related cases make up 30.2\% and $8.8 \%$, respectively. When ANCAand IgG4/MFS-combined cases (3.8\%) are included, the percentages rise to $34.0 \%$ in ANCA-related HP and $12.6 \%$ in IgG4/MFS-related HP.

compared with the response rates of the secondary surveys in recent nationwide epidemiological surveys of multiple sclerosis and myasthenia gravis conducted in Japan $39.3 \%$ and $36.9 \%$, respectively). ${ }^{3}$ We thus believe that the response rates did not impair the quality of the present study. Second, the diagnosis of HP depended on a decision by a doctor in charge, and we cannot completely neglect the possibility that the doctors in charge did not have an opportunity to thoroughly review the medical charts and radiological reports. ANCA and serum IgG4 were not examined in all patients, generating a possibility that the idiopathic HP group may contain some secondary HP cases. Third, therapeutic efficacy was based on the judgement of each doctor, yielding some uncertainty. Fourth, performance of Gd-enhanced MRI was not an inclusion criterion, which may have caused some diagnostic inaccuracy in 11 patients $(6.9 \%)$ diagnosed with non-enhanced MRI alone in the second survey.
With these reservations in mind, the prevalence of HP in Japan $(0.949 / 100000)$ is much higher than those of rare neurological diseases, such as Creutzfeldt-Jakob disease $(0.1 / 100000){ }^{8}$ Given the relapsing and progressive nature of HP without adequate medication, it casts a non-negligible healthcare burden on our society.

The most important finding of the present study is that ANCA-related disease and IgG4/MFS-related disease are the two major conditions underlying HP in Japan, where infectious causes are infrequent. Both conditions may not be mutually exclusive, and indeed, occurrence of IgG4-related HP was previously reported in association with either ANCA positivity ${ }^{9}$ or Churg-Strauss syndrome (CSS). ${ }^{10}$ However, because CSS itself shows hyper-IgG4aemia, ${ }^{11}$ increased serum IgG4 levels in ANCA-related HP may not be pathognomonic. Wegener's granulomatosis frequently produces mucosal thickening of the nasal 
Table 4 Comparison of clinical features among idiopathic, ANCA-related, and IgG4/MFS-related hypertrophic pachymeningitis cases

\begin{tabular}{|c|c|c|c|c|}
\hline & $\begin{array}{l}\text { Idiopathic } \\
\mathrm{n}=70\end{array}$ & $\begin{array}{l}\text { ANCA-related } \\
n=54\end{array}$ & $\begin{array}{l}\text { IgG4/MFS-related } \\
\mathrm{n}=14\end{array}$ & $\mathrm{p}$ Value \\
\hline Sex ratio (male:female) & 1:0.75 & 1:1.34 & 1:0.17 & $0.0126^{*}$ \\
\hline \multicolumn{5}{|l|}{ Location of hypertrophic dura } \\
\hline Cranial & $58(82.9)$ & $49(90.7)$ & $14(100.0)$ & NS \\
\hline Spinal & $9(12.9)$ & $3(5.6)$ & $0(0.0)$ & NS \\
\hline Cranial and spinal & $3(4.3)$ & $2(3.7)$ & $0(0.0)$ & NS \\
\hline Age of onset (mean $\pm S D$, years) & $54.8 \pm 16.5$ & $62.5 \pm 14.4$ & $56.7 \pm 12.5$ & $0.0183 \dagger$ \\
\hline Time between onset and diagnosis (mean $\pm \mathrm{SD}$, months) & $25.3 \pm 72.2$ & $14.6 \pm 36.6$ & $3.57 \pm 3.59$ & NS \\
\hline Age at first visit to physician (mean $\pm S D$, years) & $56.4 \pm 16.0$ & $63.5 \pm 13.6$ & $57.0 \pm 12.5$ & $0.0321 \dagger$ \\
\hline Disease duration (mean $\pm \mathrm{SD}$, months) & $49.8 \pm 52.7$ & $49.3 \pm 51.8$ & $20.3 \pm 20.7$ & NS \\
\hline \multicolumn{5}{|l|}{ Mode of onset } \\
\hline Acute & $21(30.0)$ & $12(22.2)$ & $5(35.7)$ & NS \\
\hline Subacute & 29 (41.4) & $28(51.9)$ & $8(57.1)$ & NS \\
\hline Chronic & $16(22.9)$ & $7(13.0)$ & $1(7.1)$ & NS \\
\hline Unknown & $4(5.7)$ & $7(13.0)$ & $0(0.0)$ & \\
\hline \multicolumn{5}{|l|}{ Clinical course } \\
\hline Monophasic & $23(32.9)$ & $16(29.6)$ & $9(64.3)$ & NS \\
\hline Progressive & $14(20.0)$ & $8(14.8)$ & $2(14.3)$ & NS \\
\hline Relapsing-remitting & $27(38.6)$ & $22(40.7)$ & $3(21.4)$ & NS \\
\hline Unknown & $6(8.6)$ & $8(14.8)$ & $0(0.0)$ & \\
\hline \multicolumn{5}{|l|}{ Initial symptom } \\
\hline Headache & $22(31.4)$ & $14(25.9)$ & $7(50.0)$ & NS \\
\hline Visual loss & $12(17.1)$ & $3(5.6)$ & $1(7.1)$ & NS \\
\hline Double vision & $14(20.0)$ & $2(3.7)$ & $3(21.4)$ & $0.0387 \dagger$ \\
\hline Otological symptoms & $3(4.3)$ & $12(22.2)$ & $1(7.1)$ & $0.0124 \dagger$ \\
\hline \multicolumn{5}{|l|}{ Symptoms and signs during entire course } \\
\hline Headache & $44(62.9)$ & $43(79.6)$ & $11(78.6)$ & NS \\
\hline Back pain & 6 (8.6) & $0(0.0)$ & $0(0.0)$ & NS \\
\hline Fever & $11(15.7)$ & $25(46.3)$ & $2(14.3)$ & $<0.001 \dagger$ \\
\hline Consciousness disturbance & $10(14.3)$ & $7(13.0)$ & $3(21.4)$ & NS \\
\hline Convulsion & $7(10.0)$ & $6(11.1)$ & $1(7.1)$ & NS \\
\hline Memory disturbance /higher brain dysfunction & $5(7.1)$ & $5(9.3)$ & $1(7.1)$ & NS \\
\hline Visual loss & $21(30.0)$ & $14(25.9)$ & $3(21.4)$ & NS \\
\hline Double vision & $26(37.1)$ & $8(14.8)$ & $7(50.0)$ & $0.0236 t, 0.0149 *$ \\
\hline Dysphagia & $6(8.6)$ & $4(7.4)$ & $1(7.1)$ & NS \\
\hline Dysarthria & $5(7.1)$ & $4(7.4)$ & $0(0.0)$ & NS \\
\hline Weakness (facial and/or extremities) & $22(31.4)$ & $11(20.4)$ & $1(7.1)$ & NS \\
\hline Sensory disturbance & $29(41.4)$ & $10(18.5)$ & $1(7.1)$ & $0.0321 \dagger$ \\
\hline Bladder disturbance & $6(8.6)$ & $2(3.7)$ & $0(0.0)$ & NS \\
\hline Bowel disturbance & $4(5.7)$ & $2(3.7)$ & $0(0.0)$ & NS \\
\hline \multicolumn{5}{|l|}{ Neurological findings } \\
\hline Cranial nerve palsy & $39(55.7)$ & $34(63.0)$ & $10(71.4)$ & NS \\
\hline Neck stiffness & $3(4.3)$ & $2(3.7)$ & $2(14.3)$ & NS \\
\hline Motor impairment & $14(20.0)$ & $8(14.8)$ & $1(7.1)$ & NS \\
\hline Abnormal tendon reflexes & $20(28.6)$ & $17(31.5)$ & $0(0.0)$ & NS \\
\hline Pathological reflexes & $8(11.4)$ & $4(7.4)$ & $0(0.0)$ & NS \\
\hline Limb and/or truncal ataxia & $3(4.3)$ & $2(3.7)$ & $0(0.0)$ & NS \\
\hline Decreased sensation & $24(34.3)$ & $12(22.2)$ & $0(0.0)$ & NS \\
\hline Sphincter dysfunctions & $6(8.6)$ & $2(3.7)$ & $0(0.0)$ & NS \\
\hline \multicolumn{5}{|l|}{ Laboratory data } \\
\hline WBC increase & $17(24.3)$ & $34(63.0)$ & $6(42.9)$ & $<0.001 \dagger$ \\
\hline ESR elevation & $27(38.6)$ & $34(63.0)$ & $8(57.1)$ & $0.0219 \dagger$ \\
\hline CRP elevation & $38(54.3)$ & $47(87.0)$ & $12(85.7)$ & $<0.001 \dagger$ \\
\hline \multicolumn{5}{|l|}{ Reaction to immunotherapy } \\
\hline \multicolumn{5}{|l|}{ Corticosteroids } \\
\hline Remission & $27 / 46(58.7)$ & $7 / 12(58.3)$ & $7 / 13(53.8)$ & NS \\
\hline Insufficient & 15/46 (32.6) & 4/12 (33.3) & $4 / 13(30.8)$ & NS \\
\hline Unknown & 4/46 (8.7) & $1 / 12(8.3)$ & 2/13 (15.4) & \\
\hline
\end{tabular}


Table 4 Continued

\begin{tabular}{|c|c|c|c|c|}
\hline & $\begin{array}{l}\text { Idiopathic } \\
\mathrm{n}=70\end{array}$ & $\begin{array}{l}\text { ANCA-related } \\
n=54\end{array}$ & $\begin{array}{l}\text { IgG4/MFS-related } \\
n=14\end{array}$ & p Value \\
\hline \multicolumn{5}{|c|}{ Corticosteroids+immunosuppressants } \\
\hline Remission & $3 / 14(21.4)$ & $12 / 28(42.9)$ & $0 / 1(0.0)$ & NS \\
\hline Insufficient & $9 / 14(64.3)$ & $12 / 28(42.9)$ & $1 / 1(100.0)$ & NS \\
\hline Unknown & $2 / 14(14.3)$ & 4/28 (14.3) & $0 / 1(0.0)$ & \\
\hline \multicolumn{5}{|c|}{$\begin{array}{l}\text { A p value of }<0.05 \text { has been estimated as significant among the three groups because we performed Bonferroni-Dunn's correction. When we found a significant difference amor } \\
\text { three groups, we performed a Mann-Whitney's test, Pearson's } \chi^{2} \text { test or Fisher's exact test to assess the significance of differences between groups. } \\
\text { tBetween idiopathic and ANCA-related HP. } \\
\text { *Between ANCA-related and IgG4/MFS-related HP. } \\
\text { Concerning the clinical features according to the location of hypertrophic dura, see the online supplementary table S1. } \\
\text { ANCA, antineutrophil cytoplasmic antibody; CRP, C-reactive protein; ESR, erythrocyte sedimentation rate; HP, hypertrophic pachymeningitis; MFS, multifocal fibrosclerosis; WBC, } \\
\text { white blood cells. }\end{array}$} \\
\hline
\end{tabular}

and paranasal sinuses ${ }^{12}$; therefore, its intracranial extension could produce HP. There are several reports of HP harbouring ANCA in the absence of clinically overt manifestations of Wegener's granulomatosis. ${ }^{13-15}$ We included HP cases demonstrating ANCA positivity alone in the ANCA-related HP group, because demographic features are similar between those with and without clinical manifestations of Wegener's granulomatosis.

Based on the observation that HP developed in a patient with MFS, ${ }^{16}$ a chronic fibrosing inflammation of connective tissues comprising retroperitoneal and mediastinal fibrosis, sclerosing pancreatitis and cholangitis, and Riedel's thyroiditis, ${ }^{17}$ it was proposed that HP could be a manifestation of MFS. Later, with the finding of infiltration of IgG4-positive plasma cells and hyper-IgG4aemia in lymphoplasmacytic sclerosing pancreatitis, cholangitis, sialadenitis and retroperitoneal fibrosis, MFS was supposed to be an IgG4-related disease, featuring IgG4-positive plasma cell infiltration and fibrosis in many organs. ${ }^{18}{ }^{19}$ Recent case reports of IgG4-related HP, evidenced by IgG4-positive plasma cell infiltration, show a monophasic, steroid-responsive course. $^{20} 21$ Thus, ANCA-related and IgG4/MFS-related systemic diseases might be overlooked causes of HP.

Idiopathic HP showed a slight male predominance, while ANCA-related HP showed a female preponderance and IgG4/ MFS-related HP had a marked male predominance, although there is no male or female preponderance in either ANCA-related $^{22} 23$ or IgG4/MFS-related systemic diseases. ${ }^{24}$ ANCA-related HP cases had a higher age of onset than idiopathic HP cases and IgG4/MFS-related HP cases, probably reflecting the fact that age at onset of classical CSS patients among the Japanese is around 60 years, according to the results of a nationwide survey we previously conducted. ${ }^{25}$ In terms of symptoms during the entire course, ANCA-related HP cases showed higher frequencies of fever and otological symptoms as initial symptoms, but lower frequencies of diplopia compared with idiopathic HP and IgG4/MFS-related HP cases. IgG4/ MFS-related HP cases showed a higher frequency of cranial nerve involvement but less frequent sensory disturbance/ decreased sensation. By contrast, idiopathic HP cases showed a higher frequency of double vision as an initial symptom and sensory disturbance/decreased sensation during the course. Thus, besides the differences in sex and age at onset, clinical manifestations are somewhat distinct among the three major groups of HP, which may be partly derived from the nature of the underlying diseases.

We conclude that ANCA-related disease and IgG4/MFS-related disease are the two major causes of HP in Japan. It is necessary to elucidate whether these findings, including an extremely high frequency of ANCA-related HP, are applicable to other races, by conducting large-scale epidemiological surveys in the future.

Contributors TY, HM and J-iK conceived the study, supervised the analyses and wrote the paper. TY and KS performed the statistical analyses. SU, TM, KM, NI, RY, MY, SK and KF participated in procedure development and collated the data.

Funding This study was supported in part by a Health and Labour Sciences Research Grant on Intractable Diseases (H23-Nanchitou (Nan)-Ippan-086) from the Ministry of Health, Labour and Welfare, Japan.

Competing interests TM has received speaker honoraria from Bayer Schering Pharma, Biogen Idec and Pfizer, and receives research support from Bayer Schering Pharma, the Ministry of Health, Labour and Welfare of Japan, the Japan Science and Technology Agency, the Ministry of Education, Science, Sports and Culture of Japan, and the Kaibara Morikazu Medical Science Promotion Foundation, Japan. SK has received honoraria from Teijin Pharma Limited, Nihon Pharmaceuticals Co Ltd, and Benesis Corporation. He is funded by research grants from the Ministry of Health, Labour and Welfare, Japan, and grants from the Ministry of Education, Culture, Sports, Science and Technology, Japan. J-iK is a consultant for Biogen Idec Japan, and has received honoraria from Bayer Healthcare and funding for a trip from Bayer Healthcare and Biogen Idec Japan. He is funded by a research grant for Nervous and Mental Disorders from the Ministry of Health, Labour and Welfare, Japan, and grants from the Japan Science and Technology Agency and the Ministry of Education, Culture, Sports, Science and Technology, Japan.

Ethics approval The study was approved by the Kyushu University Hospital ethical standards committee.

Provenance and peer review Not commissioned; externally peer reviewed.

\section{REFERENCES}

1 Kupersmith MJ, Martin V, Heller G, et al. Idiopathic hypertrophic pachymeningitis. Neurology 2004;62:686-94.

2 Dorr J, Elitok S, Dieste FJ, et al. Treatment-resistant chronic headaches and focal pachymeningitis in a 46-year-old man: a rare presentation of Wegener's granulomatosis. Lancet Neurol 2008;7:368-72.

3 Osoegawa M, Kira J, Fukazawa T, et al. Temporal changes and geographical differences in multiple sclerosis phenotypes in Japanese: nationwide survey results over 30 years. Mult Scler 2009;1:159-73.

4 Umehara H, Okazaki K, Masaki Y, et al. Comprehensive diagnostic criteria for IgG4-related disease (IgG4-RD), 2011. Mod Rheumatol 2012;22:21-30.

5 Hashimoto S, Fukutomi K, Nagai M, et al. Response bias in the nationwide epidemiological survey of an intracta- ble disease in Japan. J Epidemiol 1991;1:27-30.

6 Shobha N, Mahadevan A, Taly AB, et al. Hypertrophic cranial pachymeningitis in countries endemic for tuberculosis: diagnostic and therapeutic dilemmas. I Clin Neurosci 2008;15:418-27.

7 Murai $\mathrm{H}$, Yamashita N, Watanabe M, et al. Characteristics of myasthenia gravis according to onset-age: Japanese nationwide survey. J Neuro/ Sci 2011;305:97-102.

8 Nozaki I, Hamaguchi T, Sanjo N, et al. Prospective 10-year surveillance of human prion diseases in Japan. Brain 2010;133:3043-57.

9 Iguchi A, Wada Y, Kobayashi D, et al. A case of MPO- and PR3-ANCA-positive hypertrophic cranial pachymeningitis with elevated serum IgG4. Mod Rheumatol 2013;23:151-5 
10 Della Torre E, Bozzolo EP, Passerini G, et al. lgG4-related pachymeningitis: evidence of intrathecal IgG4 on cerebrospinal fluid analysis. Ann Intern Med 2012; 156:401-3.

11 Vaglio A, Strehl JD, Manger B, et al. IgG4 immune response in Churg-Strauss syndrome. Ann Rheum Dis 2012:71:390-3.

12 Mujagic S, Sarihodzic S, Huseinagic $H$, et al. Wegener's granulomatosis of the paranasal sinuses with orbital and central nervous system involvement-diagnostic imaging. Acta Neurol Belg 2011;111:241-4.

13 Takuma $H$, Shimada $H$, Inoue $Y$, et al. Hypertrophic pachymeningitis with anti-neutrophil cytoplasmic antibody (p-ANCA), and diabetes insipidus. Acta Neurol Scand 2001;104:397-401.

14 Horino T, Takao T, Taniguchi Y, et al. Hypertrophic pachymeningitis with MPO-ANCA-positive vasculitis. Clin Rheumatol 2010;29:111-13.

15 Peng $W$, Wang $X$. Hypertrophic pachymeningitis and cerebral infarction resulting from ANCA-associated vasculitis. Neurol India 2012;60:424-6.

16 Berger JR, Snodgrass S, Glaser J, et al. Multifocal fibrosclerosis with hypertrophic intracranial pachymeningitis. Neurology 1989;39:1345-9.

17 Comings DE, Skubi KB, Van Eyes J, et al. Familial multifocal fibrosclerosis. Findings suggesting that retroperitoneal fibrosis, mediastinal fibrosis, sclerosing cholangitis, Riedel's thyroiditis, and pseudotumor of the orbit may be different manifestations of a single disease. Ann Intern Med 1967;66:884-92.
18 Yamamoto M, Takahashi H, Ohara M, et al. A new conceptualization for Mikulicz's disease as an IgG4-related plasmacytic disease. Mod Rheumatol 2006; $16: 335-40$

19 Kamisawa T, Nakajima H, Egawa N, et al. IgG4-related sclerosing disease incorporating sclerosing pancreatitis, cholangitis, sialadenitis and retroperitoneal fibrosis with lymphadenopathy. Pancreatology 2006;6:132-7.

20 Kitano A, Shimomura T, Okada A, et al. Multifocal fibrosclerosis with intracranial pachymeningitis. Intern Med 1995;34:267-71.

21 Kim EH, Kim SH, Cho JM, et al. Immunoglobulin G4-related hypertrophic pachymeningitis involving cerebral parenchyma. J Neurosurg 2011; 115:1242-7.

22 Suzuki Y, Takeda Y, Sato D, et al. Clinicoepidemiological manifestations of RPGN and ANCA-associated vasculitides: an 11-year retrospective hospital-based study in Japan. Mod Rheumatol 2010;20:54-62.

23 Fujimoto S, Watts RA, Kobayashi S, et al. Comparison of the epidemiology of anti-neutrophil cytoplasmic antibody-associated vasculitis between Japan and the $\mathrm{U}$. K. Rheumatology (Oxford) 2011;50:1916-20.

24 Zen Y, Nakanuma Y. IgG4-related disease: a cross-sectional study of 114 cases. Am J Surg Pathol 2010;34:1812-19.

25 Isobe N, Kira J, Kawamura N, et al. Neural damage associated with atopic diathesis: a nationwide survey in Japan. Neurology 2009;73:790-7. 


\section{A nationwide survey of hypertrophic pachymeningitis in Japan}

Tomomi Yonekawa, Hiroyuki Murai, Satoshi Utsuki, et al.

J Neurol Neurosurg Psychiatry published online November 22, 2013

doi: 10.1136/jnnp-2013-306410

Updated information and services can be found at:

http://jnnp.bmj.com/content/early/2013/11/22/jnnp-2013-306410.full.html

\section{These include:}

\section{Data Supplement "Supplementary Data"}

http://jnnp.bmj.com/content/suppl/2013/11/22/jnnp-2013-306410.DC1.html

References This article cites 25 articles, 3 of which can be accessed free at: http://jnnp.bmj.com/content/early/2013/11/22/jnnp-2013-306410.full.html\#ref-list-1

$\mathbf{P}<\mathbf{P} \quad$ Published online November 22, 2013 in advance of the print journal.

Email alerting

Receive free email alerts when new articles cite this article. Sign up in service the box at the top right corner of the online article.

Topic Articles on similar topics can be found in the following collections Collections
Infection (neurology) (422 articles)
Immunology (including allergy) (1576 articles)
Ophthalmology (723 articles)

Advance online articles have been peer reviewed, accepted for publication, edited and typeset, but have not not yet appeared in the paper journal. Advance online articles are citable and establish publication priority; they are indexed by PubMed from initial publication. Citations to Advance online articles must include the digital object identifier (DOIs) and date of initial publication.

To request permissions go to:

http://group.bmj.com/group/rights-licensing/permissions

To order reprints go to:

http://journals.bmj.com/cgi/reprintform

To subscribe to BMJ go to:

http://group.bmj.com/subscribe/ 


\section{Notes}

Advance online articles have been peer reviewed, accepted for publication, edited and typeset, but have not not yet appeared in the paper journal. Advance online articles are citable and establish publication priority; they are indexed by PubMed from initial publication. Citations to Advance online articles must include the digital object identifier (DOIs) and date of initial publication.

To request permissions go to:

http://group.bmj.com/group/rights-licensing/permissions

To order reprints go to:

http://journals.bmj.com/cgi/reprintform

To subscribe to BMJ go to:

http://group.bmj.com/subscribe/ 